\title{
Repair of extra-anatomic bypass graft structural degeneration and pseudoaneurysm with endovascular stent-graft relining
}

\author{
Elizabeth H. Stephens, MD, PhD, ${ }^{\mathrm{a}}$ Dominik Fleischmann, MD, ${ }^{\mathrm{b}}$ Albert Starr, MD, ${ }^{\mathrm{c}}$ and \\ D. Craig Miller, MD, ${ }^{d}$ Rochester, Minn; Stanford, Calif; and Portland, Ore
}

\footnotetext{
From the ${ }^{\mathrm{a}}$ Department of Cardiovascular Surgery, Mayo Clinic, Rochester, Minn; Departments of ${ }^{\mathrm{b}}$ Radiology and ${ }^{\mathrm{d}}$ Cardiothoracic Surgery, Stanford University Medical Center, Stanford, Calif; and ${ }^{\mathrm{c}}$ Knight Cardiovascular Institute, Oregon Health and Science University, Portland, Ore.

Disclosures: The authors reported no conflicts of interest.

The Journal policy requires editors and reviewers to disclose conflicts of interest and to decline handling or reviewing manuscripts for which they may have a conflict of interest. The editors and reviewers of this article have no conflicts of interest.

Received for publication April 6, 2020; revisions received April 6, 2020; accepted for publication April 14, 2020; available ahead of print July 2, 2020.

Address for reprints: D. Craig Miller, MD, Department of Cardiothoracic Surgery, Falk CV Research Center, Stanford University Medical School, 300 Pasteur Dr, MC 5407, Stanford, CA 94305-5407 (E-mail: dcm@ stanford.edu).

JTCVS Techniques 2020;3:259-62

2666-2507

Copyright (c) 2020 The Authors. Published by Elsevier Inc. on behalf of The American Association for Thoracic Surgery. This is an open access article under the CC BY-NC-ND license (http://creativecommons.org/licenses/bync-nd/4.0/).

https://doi.org/10.1016/j.xjtc.2020.04.030
}

Video clip is available online.

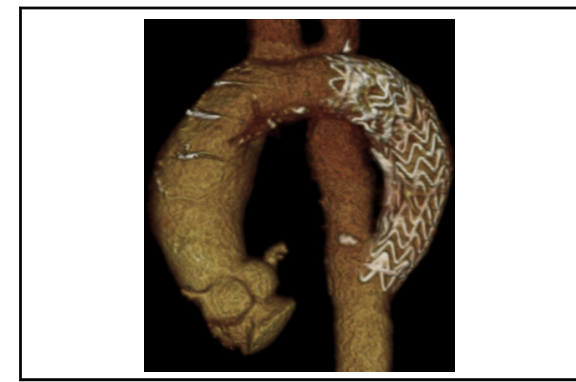

Imaging 8 years postoperatively showing patent "re-lined" extra-anatomic graft.

CENTRAL MESSAGE

Thirty years after extra-anatomic Dacron graft coarctation repair, a pseudoaneurysm secondary to graft degeneration required surgery.

See Commentary on page 263.
This patient with aortic coarctation and a bicuspid aortic valve underwent end-to-end coarctation repair at age 5 years. Four years later, the patient developed recurrent coarctation that was repaired by Dr Albert Starr with an extra-anatomic bypass graft from the ascending aorta to the mid-descending thoracic aorta using a 14-mm knitted Dacron graft. The patient remained asymptomatic; however, a computed tomographic angiogram scan 33 years later in 2010 revealed a $6.2 \times 4.5-\mathrm{cm}$ pseudoaneurysm of the extra-anatomic bypass and a stenotic proximal anastomosis (Figure 1 and Video 1).

Surgical repair was performed in January 2011 through a median sternotomy, reopening the sternum with cardiopulmonary bypass via axillary and femoral cannulation followed by hypothermic circulatory arrest $\left(22^{\circ} \mathrm{C}\right)$ and selective antegrade cerebral perfusion. On inspection, the proximal portion of the graft had eroded through the cortex of the posterior sternal table (Figure 1,C). A 3-cm longitudinal tear in the deteriorating knitted graft was the origin of the pseudoaneurysm. A 22-mm Hemashield woven doublevelour Dacron graft (Maquet, Wayne, NJ) was anastomosed end-to-end to the distal extra-anatomic graft. The old graft was diffusely degenerated and judged inadequate to hold sutures. Therefore, a 28-mm $\times 15-\mathrm{mm}$ gore TAG stent-graft (W. L. Gore and Associates, Flagstaff, Ariz) was deployed under transesophageal echo guidance through the new and old grafts extending into the descending aorta, thereby "re-lining" the remaining old graft and distal descending aortic anastomosis. Proximally, the old, stenotic graft was resected and the new 22-mm Dacron graft was anastomosed end-to-side to the native ascending aorta (Figure 2, Video 2).

The patient recovered uneventfully. An early postoperative computed tomographic angiogram revealed a widely patent extra-anatomic graft (Figure 2). The patient continues to do well. Eight years postoperatively, imaging demonstrated an intact repair (Figure 3) with a wellfunctioning bicuspid aortic valve and unchanged mitral regurgitation. The patient provided informed consent for the publication of the study data.

While extra-anatomic bypasses with various grafts have been performed over many decades, the reported durability 


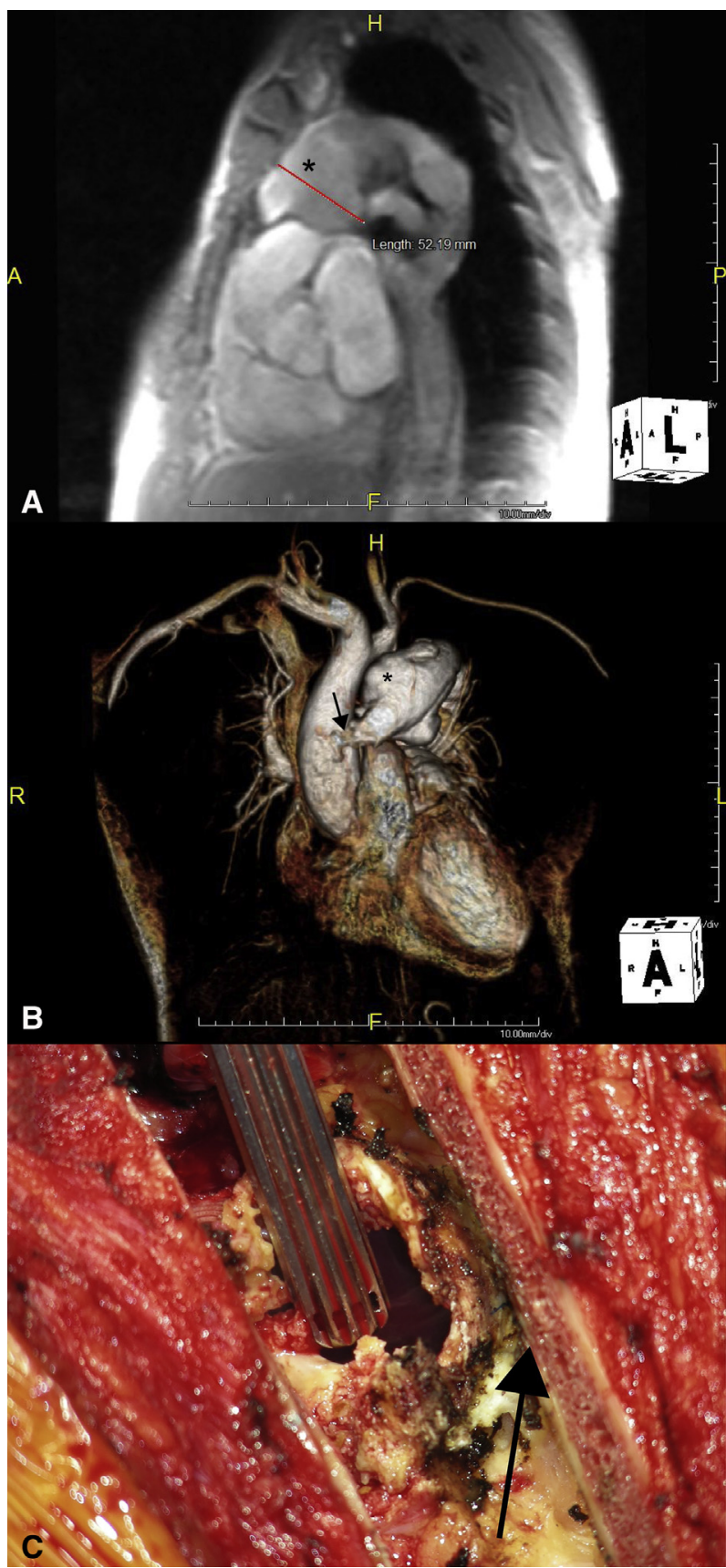

FIGURE 1. Preoperative magnetic resonance imaging of extra-anatomic bypass showing (A) 5.2-cm pseudoaneurysm $\left(^{*}\right.$ ) and in 3-dimensional reconstruction (B) stenosis at the anastomosis to the native ascending aorta (arrow, 1-cm diameter) along with pseudoaneurysm (*). C, Intraoperative photograph demonstrating erosion of the extra-anatomic bypass graft through the cortex of the posterior sternal table (arrow).

of these repairs has varied considerably. This issue of graft durability is especially important for the pediatric population with a long life expectancy. Fabric graft deterioration, as in the case of this patient, may lead to pseudoaneurysm formation with a high likelihood of rupture. Over the

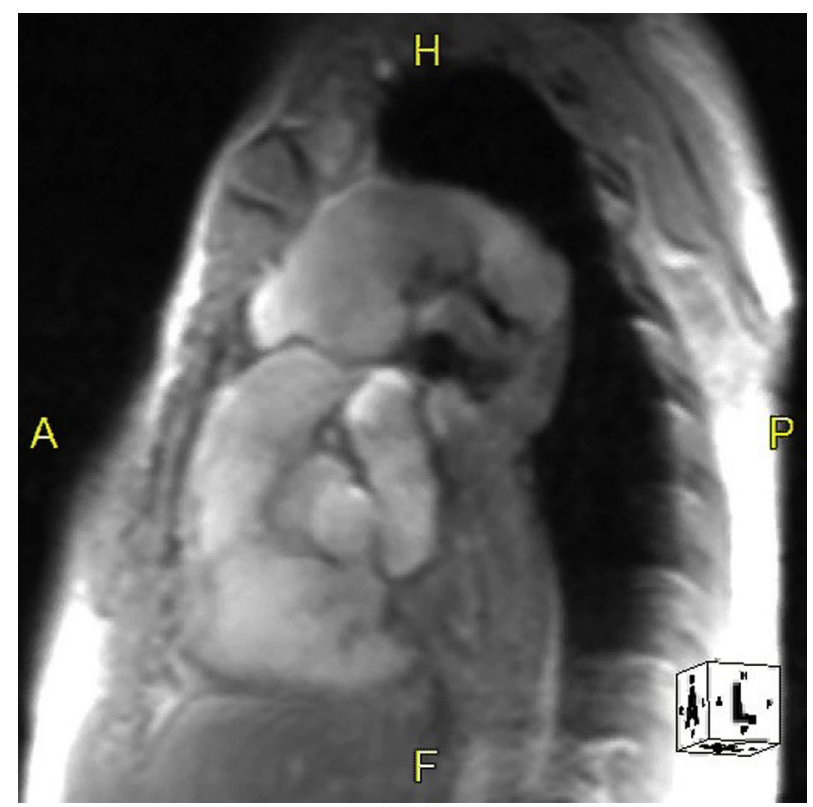

VIDEO 1. Magnetic resonance imaging demonstrating coarctation of the native aorta and extra-anatomic bypass from ascending to descending aorta. Video available at: https://www.jtcvs.org/article/S2666-2507(20) 30323-0/fulltext.

years, the materials used for aortic repairs have changed dramatically, ranging from cellophane used to wrap Albert Einstein's abdominal aortic aneurysm, ${ }^{1}$ to Blakemoore and Voorhees' Vinyon "N" cloth constructed into tubular conduits on a sewing machine, ${ }^{2}$ to Dacron and Teflon vascular grafts, and more recently collagen or gelatin-impregnated polyester (Dacron) woven grafts. Although nylon grafts were initially used, their loss of tensile strength prompted surgeons to abandon them. ${ }^{2}$ Clearly, the causes for graft failure are multifactorial and patient dependent; however, studies have shown that knitted Dacron grafts lose strength initially but then stabilize or lose tensile strength slowly, whereas Teflon grafts maintain their strength for at least 18 years in experimental studies. ${ }^{2}$ Dacron grafts absorb $0.1 \%$ of their water weight (vs $0 \%$ for Teflon), which hypothetically may act as weak acids, attacking the Dacron and contributing to the slow loss of tensile strength of certain Dacron grafts, ${ }^{3}$ leading some to recommend Teflon grafts for younger patients. ${ }^{2}$ Modern woven Dacron prostheses used since the 1980s are more reliable; the Meadox (now Maquet) woven double-velour Dacron grafts do not dilate over time, whereas all knitted grafts and Gelweave woven grafts (Vascutek Terumo Aortic, Inc, Renfrewshire, Scotland, United Kingdom) can dilate. Experimental studies suggested that Dacron double-velour grafts healed more completely with a capsule densely adherent to the Dacron substrate, providing resistance to infection and less pronounced internal neointimal proliferation causing stenosis. ${ }^{4}$ 


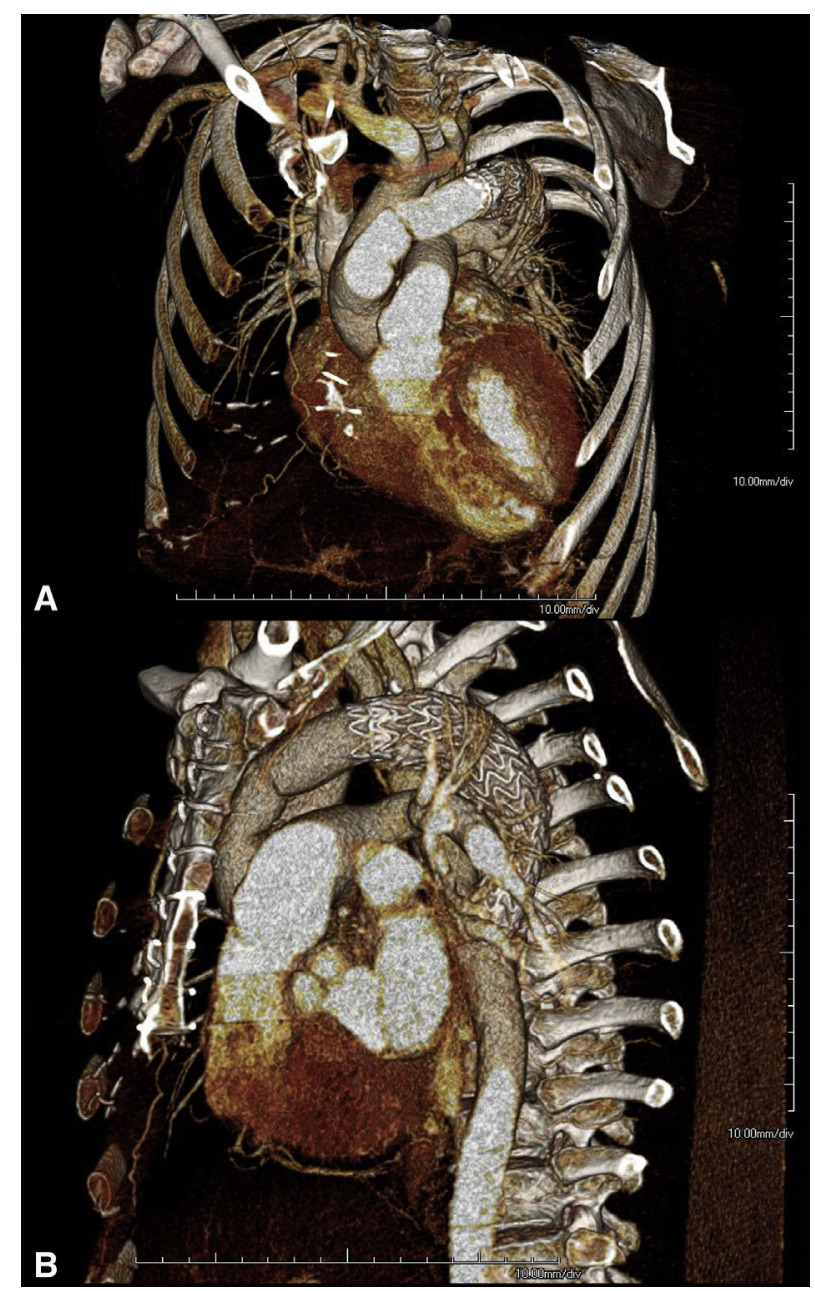

FIGURE 2. A and B, Three-dimensional reconstruction of early postoperative computed tomographic showing the new vascular graft with a widely patent proximal anastomoses to the native aorta and the endovascular stent graft relining the previous extra-anatomic graft.

The DeBakey Ultra lightweight knitted Dacron grafts (BD BARD; Bard Medical Division, Covington, Ga) used in the remote past for vascular surgery were found to degrade unpredictably with catastrophic consequences. ${ }^{2}$ In the present case, the specific type of Dacron graft is unknown; however, it is likely that this graft was a knitted Dacron peripheral vascular graft or possibly a DeBakey Ultra lightweight knitted graft based on the consistency of the remaining graft. This case highlights the importance of indefinite imaging surveillance for all patients who underwent such repairs early in life, even in the absence of symptoms concerning for vascular graft dysfunction.

The use of a nitinol-based polytetrafluorethylene (Teflon)-lined stent graft (GORE TAG) in this case was

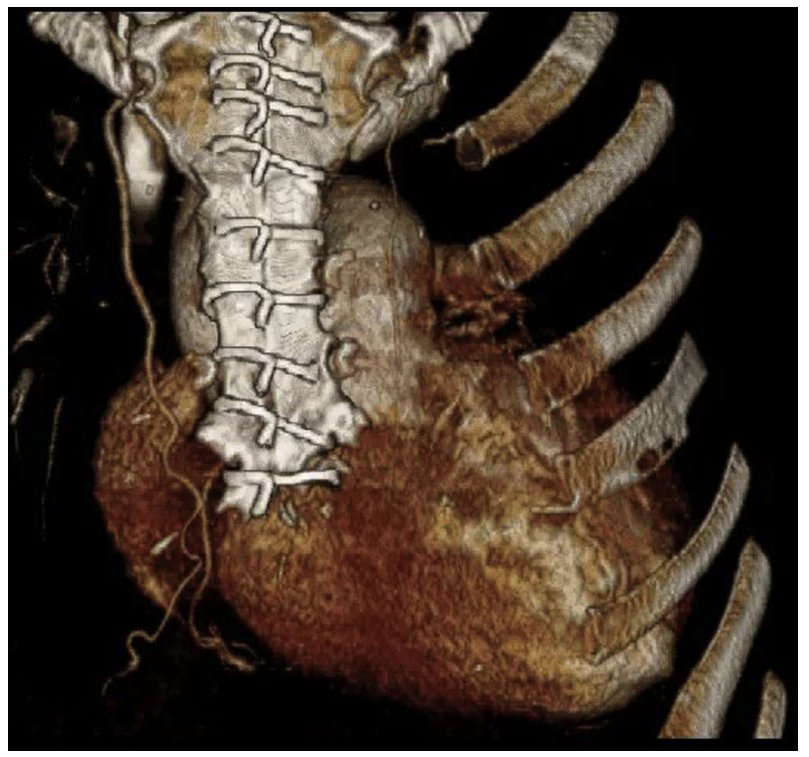

VIDEO 2. Three-dimensional reconstruction of early postoperative computed tomographic imaging demonstrating the new graft anastomosed to the native aorta and endovascular stent graft "relining" the remaining extra-anatomic graft. Video available at: https://www.jtcvs.org/article/ S2666-2507(20)30323-0/fulltext.

based on expediency when the old graft was found to be severely degenerated. Since Nitinol will also degenerate over the years, ${ }^{5}$ this admonition for indefinite life-long serial imaging should also apply to all patients with a stentgraft.

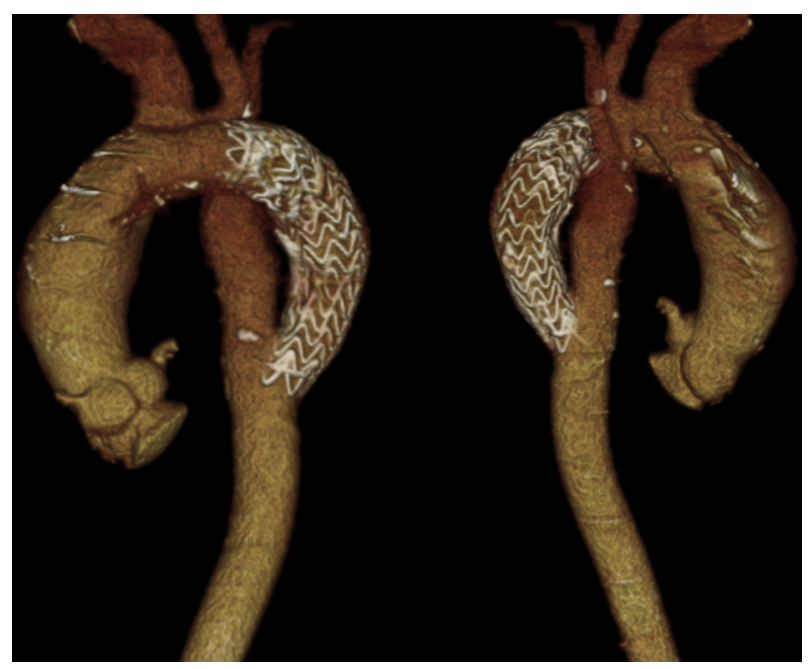

FIGURE 3. Three-dimensional volume-rendered computed tomographic angiogram of the aortic arch and extra-anatomic graft 8 years postoperatively showing patent "re-lined" extra-anatomic graft. 


\section{References}

1. Bollinger A, Ruttimann B. Aneurysms from the viewpoint of medical history [in German]. Vasa. 2002;31:281-6.

2. Edwards WS. Arterial grafts: past, present, and future. Arch Surg. 1978;113:1225-33.

3. Berger K, Sauvage LR. Late fiber deterioration in Dacron arterial grafts. Ann Surg. 1981;193:477-91.
4. Moore WS, Malone JM, Keown K. Prosthetic arterial graft material. Influence on neointimal healing and bacteremic infectibility. Arch Surg. 1980;115: 1379-83.

5. Stoeckel D, Pelton A, Duerig T. Self-expanding nitinol stents: material and design considerations. Eur Radiol. 2004;14:292-301. 